\title{
Controlled Porosity Alumina Structures for Ultra-Precision Hydrostatic Journal Bearings via Starch Consolidation
}

\author{
Isidro S. Durazo-Cardenas ${ }^{*}$, David J. Stephenson, John Corbett \\ Cranfield University, Cranfield, Bedfordshire. MK43 0AL. UK
}

\begin{abstract}
In the present work, a series of fine grade alumina powders has been used in combination with maize starch granules to produce porous structures for porous hydrostatic journal bearing applications. A comprehensive series of tests were conducted to characterize porosity in terms of density, pore size and permeability.

Successful processing of quality journal bearing components has been demonstrated for preferred combinations of alumina size and starch content, using fixed processing parameters. The new porous ceramic bearings showed consistent and reproducible properties and are suitable for a wide range of higher precision engineering applications. The porous ceramic bearing processing route has also proved to be low cost and environmentally sound.
\end{abstract}

Keywords: Porous ceramic bearings, porosity, permeability, starch, hydrostatic bearings

\footnotetext{
* Corresponding author. Email: i.s.durazocardenas@cranfield.ac.uk. Tel: 44 (0) 1234 750111, Fax: 44 (0) 1234 752946
} 


\section{Introduction}

Porous-ceramic hydrostatic journal bearings have been successfully developed in a previous research program [1]. These bearings demonstrated superior stiffness and thermal performance characteristics compared with conventional hydrostatic journal bearings of the same size [2]. Because of these advantages, porous ceramic hydrostatic bearings can be considered a viable solution to the most severe demands for higher accuracy and overall performance levels required by ultra precision spindle bearing systems [3]. In satisfying these demands, the enabling of new machining process capabilities and product development [4] can be achieved. Typical applications of porous ceramic bearings are single point diamond turning and grinding spindles.

In porous ceramic bearings, a journal bearing has the simple shape of a hollow cylinder. The externally pressurized lubricant is supplied to the bearing gap through the extremely large number of integrated restrictors in the ceramic bearing's porous wall, as opposed to the more complex 4-6 restrictor/pocket arrangement typically found in conventional metal hydrostatic bearings [5]. This results in an improved fluid film pressure distribution and an enhanced hydrodynamic component, which in turn improve the overall bearing load capacity and stiffness [6]. As a consequence of the porous bearing's operation principle, adequate processing control of the porous wall microstructure, in terms of uniform and predictable permeability, is of paramount importance.

Traditionally, powder metallurgy techniques have been employed to produce bronze or iron porous journal bearings. However, difficulties in controlling porosity consistently [7] often results in variable permeability across bearing batches. Partial pore closure during final 
machining [8], as well as localized plastic deformation caused by pressurized lubricant [9], both resulting in the alteration of the bearing permeability, have also been reported in the literature. The most significant advantages of ceramics compared with traditional porous bearing materials can be summarized as follows [1]:

- can be machined without pore 'smearing'

- wear resistant

- corrosion resistant

- low coefficient of thermal expansion

- can be used at relatively high temperatures

Despite all the benefits, porous ceramic hydrostatic journal bearings have yet to be embraced by precision engineers and machine tool designers. So far, the main obstacle has been the intricacy of the bearing's processing method, hot isostatic pressing (HIP). This method proved to be successful for the manufacture of journal bearings. However, so far, only journal bearings of 50mm inside diameter and 50mm long have been achieved [1], which limits their application. The HIP processing of porous ceramics essentially consists of vibration packing of mono sized $7 \mu \mathrm{m}$ alumina powder, or bimodal blends of 1 and $13 \mathrm{um}$, followed by partial sintering in a high pressure argon environment [1] [10]. However, a significant level of machining is required and HIP is a relatively expensive process. There are further disadvantages to HIP of porous ceramic bearings that limit their range of applications. For example, HIP of finer powders is difficult to achieve without agglomeration, resulting in non-uniform permeability. Also, it is difficult to achieve uniform permeability as the size of the components increase. Hence the need to establish an optimized alternative porous ceramic processing method that enables the production 
of cost-effective porous ceramic bearings suitable for a wider range of high precision engineering applications.

Amongst the available ceramic processing routes, the starch consolidation technique (SC) [11] offers the ability to produce porous ceramic components with controllable porosity and with a wide range of shapes and geometries in a simple and cost effective manner. The foundations of the starch consolidation technique were laid formally by Lyckfeldt and Ferreira [11]. Further developments have been subsequently reported by other researchers [12] [13] [14]. In this processing technique, the starch granules act as binder and pore former. A ceramic slip is formed by mixing fine ceramic powders with starch and water. The slip is then cast into an impermeable mould of the desired geometry and heated up to around $65^{\circ} \mathrm{C}$ for $1-2 \mathrm{~h}$. This causes the starch/ceramic slip to 'gel', and its consequent solidification into a ceramic body. After de-molding and drying of the ceramic body, the starch particles are burnt out in a subsequent furnace operation that leads to the ceramic body densification, leaving corresponding voids within the ceramic body. The resulting porosity is related to the amount and shape of the original starch granules. From a processing point of view, the bearing's level of porosity is effectively controlled by carefully manipulating the amount of starch in the slip and also by adjusting other processing parameters such as the total solids loading and the sintering temperature profile. The starch consolidation (SC) technique's systematic approach for controlling the component's porosity, in addition to its cost effectiveness as well as geometry and shape flexibility, make this technique very attractive for the manufacture of porous ceramic hydrostatic bearings. The simplicity and higher reliability of the SC over the HIP process, results in estimated savings of $36 \%$ in the overall cost per single journal bearing [15]. 
The authors have recently examined the performance of an ultra-precision alumina porous ceramic hydrostatic journal bearing processed via the starch consolidation technique and have compared this with the performance of a conventional hydrostatic bearing [16]. The SC bearing showed improved performance characteristics over the conventional one in terms of stiffness (95\%), temperature rise $(50 \%)$ and flow rate $(64 \%)$. The performance of this SC bearing was in agreement with that of a HIP processed bearing [2]. However, in depth details of the examined SC bearing processing have been not described before.

In this study, a new processing route for the manufacture of porous ceramic hydrostatic bearings is presented. Bearings of various geometries and shapes have been produced within a range of porous wall permeability values that are suitable for practical ultra-precision engineering applications.

\section{Experimental}

\subsection{Porous ceramic material requirements}

Permeability is widely acknowledged as the most significant physical property of a porous material used for externally pressurized porous bearing applications. Consistent, uniform and repeatable permeability are the most significant attributes demanded from a processing method for externally pressurized porous ceramic bearings. The bearing's permeability coefficients, together with other design parameters such as the bearing gap and the bearing dimensions, determine the overall bearing performance [6].

Previous mathematical modeling [2] based on the work of Chattopadhyay and Majumdar [6] has

identified an optimum value of permeability of $1 \times 10^{-14} \mathrm{~m}^{2}$, for a typical ultra-precision hydrostatic journal bearing observing a limited deflection of $1 \mu \mathrm{m}$. The model considers a 
bearing of $50 \mathrm{~mm} \mathrm{ID}$, length of $50 \mathrm{~mm}$ and wall thickness of $6 \mathrm{~mm}$, using a working gap of $15 \mu \mathrm{m}$. Permeability is closely related to the density and the pore size distribution of the ceramic matrix. Further modeling [2] based on the Kozeny theory [17] has been used to estimate a theoretical value of fractional porosity of $20 \%$ and average pore-size of $3 \mu \mathrm{m}$, considering an optimum permeability of $1 \times 10^{-14} \mathrm{~m}^{2}$. Therefore these values for permeability, porosity and pore size were chosen as initial material characteristics for the development of prototype bearings.

\subsection{Processing of porous bearing samples}

The scheme proposed by Lyckfeldt and Ferreira [11] for the processing of porous ceramics by starch consolidation was adapted for porous ceramic bearings. The shape of the porous bearings was that of journal bearings (hollow cylinders) with an internal diameter (ID) of 50mm, length of $50 \mathrm{~mm}$ and a wall thickness of $6 \mathrm{~mm}$. This size of bearing was favored because of readily available porous ceramic performance test rigs, permitting the validation of porous journal bearing theory.

In addition, porous ceramic discs were also processed for pore structure characterization. These were primarily of $46 \mathrm{~mm}$ in diameter with thickness of $7 \mathrm{~mm}$.

\subsubsection{Slip preparation}

All ceramic slips were prepared with mono-sized alumina powders. A range of alumina powders (Alcan Chemicals Europe, UK) with average particle sizes ranging from 0.5 to $7 \mu \mathrm{m}$ were used in the present work. Native maize starch (CERESTAR UK Ltd., C*03401) was used as binder 
and pore former, while poly-acrylic acid, (Allied Colloids, Dispex A40), was used as a dispersant. Further details of the materials used in this work are listed in Table 1.

All powders, including starch were dried at $120^{\circ} \mathrm{C}$ for $24 \mathrm{~h}$ before mixing. Based on previous studies [11], the slip total solids-loading was set to 59.1 volumetric $\%$. The first variable was the starch content and this was incremented in $10 \%$ volumetric steps of the solids loading. A second variable was the alumina powder particle size, which ranged from 0.5 to $7 \mu \mathrm{m}$ for each aluminastarch slip formulation. Slip batches of $500 \mathrm{~g}$ solids were prepared. The alumina and starch density values used in the slip formulation were $3.98 \mathrm{~g} / \mathrm{cm}^{3}$ and $0.56 \mathrm{~g} / \mathrm{cm}^{3}$, respectively. The effects of the starch content and alumina particle size were subsequently examined with regard to the bearings physical properties such as density and permeability.

After the slip formulation and alumina particle size were defined for each batch, the required raw materials were weighed and poured into a 1 liter pot and ball milled for $24 \mathrm{~h}$ at $66 \mathrm{rpm}$ using spherical alumina grinding media ranging from 5 to $15.5 \mathrm{~mm}$ in diameter. In order to avoid air entrainment, the ceramic slips were vacuum de-gassed before the forming operation.

\subsubsection{Forming}

The ceramic slip was poured into the moulds and then heated in an air circulating oven at $65{ }^{\circ} \mathrm{C}$. Forming times varied from 2 to 5 hours depending on the slip volume and size of the castings. The relatively complex hollow-cylinder shape of the journal bearing castings was achieved by using moulds comprising of four parts: base, sleeve, lid and a core. Moulds were made of aluminum alloy, due to its good strength, machinability, low density and corrosion resistance.

Initial trials showed that it was necessary to use a release agent, and the most effective was a non-silicone type spray applied to the mould walls prior to casting. 
After consolidation, the bearing castings were sufficiently strong to be de-molded without any significant deformation. The castings were then dried for 24 hours at $120^{\circ} \mathrm{C}$ prior to sintering.

\subsubsection{Binder burnout and sintering}

The furnace cycle processing defined by Lyckfeldt and Ferreira [11] was used. This included binder burnout, pre-sintering and sintering steps carried out in one integrated operation. The equipment used was a box furnace fitted with a $0.1^{\circ} \mathrm{C}$ resolution controller. The temperature limit was $1600^{\circ} \mathrm{C}$. The starch granules were burned out at a slow heating rate of $1{ }^{\circ} \mathrm{C} / \mathrm{min}$ up to $500^{\circ} \mathrm{C}$, with 1 hour holds at 200 and $300^{\circ} \mathrm{C}$. The pre-sintering and sintering operations were conducted within a similar heating rate observing temperature holds of 1 hour at $1000^{\circ} \mathrm{C}$ and 2 hours at $1550^{\circ} \mathrm{C}$, respectively. These conditions were kept constant throughout the research.

\subsubsection{Machining of porous ceramic bearings}

Although the bearings produced were near net shape, grinding was still needed to achieve the final size and the geometric tolerance necessary for assembly and subsequent bearing performance testing. This required the ceramic bearings to be precision machined to enable typical hydrostatic bearing radial gaps of around $20 \mu \mathrm{m}$. Conventional grinding machines using diamond wheels were used. Typical roughness values achieved by the grinding process were in the order of $1 \mu \mathrm{m} \mathrm{Ra}$.

\subsubsection{Measurement of porosity and density}

Porosity and density measurements were conducted on ground bearing specimens, via BS EN ISO 2738:2000 [18]. In this procedure, porosity is estimated using Archimedes' principle. This essentially consists of weighing the porous specimens dried, fully impregnated while suspended 
in water, and finally free standing while impregnated to calculate open and closed porosity, bulk density and volume of pores.

The bearing's bulk density, and open porosity were calculated using the following formulas:

$$
\begin{aligned}
& B=\frac{m_{2} \cdot \rho_{w}}{m_{3}-m_{w}} \\
& \xi_{o}=\frac{m_{3}-m_{2}}{m_{3}-m_{w}} \times 100
\end{aligned}
$$

$B$ is the bulk density of the test piece in $\mathrm{g} / \mathrm{cm}^{3}, \xi_{0}$ is the open porosity percentage, $m_{2}$ is the mass of the dried test piece in $\mathrm{g}, m_{3}$ is the mass of the fully impregnated test piece in $\mathrm{g}, m_{w}$ is the mass of the fully impregnated test piece suspended in water in $\mathrm{g}$ and $\rho_{w}$ is the density of water in $\mathrm{g} / \mathrm{cm}^{3}$.

Water impregnation of the specimens was conducted in a vacuum chamber. To ensure consistency, all specimens were first dried for $24 \mathrm{~h}$ at $120^{\circ} \mathrm{C}$ and the evacuation time was set to a minimum of 15 minutes, until all bubbling stopped. Weighing was conducted using an electronic balance with a $1 \mu \mathrm{g}$ resolution.

\subsubsection{Pore size distribution \& microstructure}

In the present study, pore size distribution was assessed by a combination of adjunct techniques: bubble test, water expulsion method and SEM micrograph studies. The bubble test and the water expulsion test method were used to assess pores that correspond to the equivalent connecting contact areas or necks between the larger spherical shaped pores left by the original starch granules. The assessment of pores using the bubble test and the water expulsion method used 
disc-shaped specimens that were $46 \mathrm{~mm}$ in diameter and thickness of $7 \mathrm{~mm}$. These specimens were processed with the same slip composition and conditions as those of the journal bearings. Density and permeability measurements, together with microscopy studies confirmed that comparable structures were produced.

The bubble test was performed in accordance with standard BS EN 24003 [19]. The test specimen was first fully impregnated with de-ionized water (Figure 1). One of the specimen surfaces was further covered with a known column of water $\left(h_{w}\right)$. Pressurized air was gradually passed through the specimen from the opposite surface. The pressure $\left(p_{1}\right)$ at which the first bubble begins to emerge on the top submerged surface, known as the first bubble point is used to calculate the maximum equivalent capillary diameter of the pore:

$$
d_{\max }=\frac{4 \cdot \gamma_{w}}{p_{1}+\rho_{w} \cdot g \cdot h_{w}}
$$

Where $d_{\max }$ is the maximum circular-capillary-equivalent pore diameter in $\mathrm{m}, \gamma_{\mathrm{w}}$ is the surface tension of water in $\mathrm{N} / \mathrm{m}, p_{1}$ is the absolute gas pressure upstream the specimen in $\mathrm{Pa}, \rho_{\mathrm{w}}$ is the density of de-ionized water in $\mathrm{kg} / \mathrm{m}^{3}, g$ is the gravitational acceleration constant $\mathrm{m} / \mathrm{s}^{2}$ and $h_{w}$ is the height of the water column above the specimen in $\mathrm{m}$.

In the water expulsion method, compressed air is passed through a porous specimen fully impregnated with water. The compressed air pressure is gradually increased until it overcomes the water's surface tension in the largest pore, expelling it. As the air pressure is increased, more water is expelled from an increasing number of pores of decreasing size. The pressure difference 
$P_{0}$ and volume flow across the specimen $Q$ are measured throughout the procedure. This enables the estimation of the equivalent pore size and the number of pores to be determined:

$$
P_{0}=\frac{p_{1}^{2}-p_{2}^{2}}{2-p_{r e f}}
$$

Where $p_{1}$ is the absolute air pressure upstream of the specimen in $\mathrm{Pa}, p_{2}$ is the absolute air pressure downstream of the specimen in $\mathrm{Pa}$ and $p_{\text {ref }}$ is the absolute air pressure in $\mathrm{Pa}$ at which flow rate is measured. For each pressure increment, the equivalent pore size corresponding to the resulting differential pressure, and the number of pores contributing to the corresponding airflow increment were calculated using Gelinas and Angers method [20]. Figure 2 illustrates the water expulsion method experimental set up. Successful characterization of the pore size distribution using water expulsion for porous ceramic bearings has been reported before [2] [21].

Scanning electron microscopy (SEM) was used to study the sintered specimens' microstructure. These studies were primarily concerned with the overall pore structure formed by the voids left by starch particles. From a selection of journal bearings, one centre section was acutely sliced to expose a surface layer extending through the bearing's wall. These specimens were then mounted in resin and progressively polished using diamond grinding discs. Finally they were polished using a fine diamond suspension on hard cloth. Following the specimens' preparation, a series of micrographs were taken. 


\subsubsection{Permeability measurements}

The permeability of the porous ceramic journal bearings was measured using a specially designed test rig compliant with standard BS 5600 [22]. During measurement, each ground journal bearing was clamped axially between 2 flat sealing surfaces. Pressurized fluid applied from the outside of the bearing permeated inwards through the bearing wall. Figure 3 illustrates the permeability measurement set-up for porous journals. Ten pressure drop and volume flow readings were taken. The pressure differential across the bearing ranged from 0.1 to $1.0 \mathrm{MPa}$. These pressures were measured using a differential pressure sensor connected across the bearing. Mass flow measurement was achieved by collecting the out-flowing test liquid with a weigh tank. The electronic balance had a resolution of $0.01 \mathrm{~g}$. The test fluid was mineral oil (BP's HP0). Viscosity and density values of $1.45 \mathrm{~mm}^{2} / \mathrm{s}$ and $787 \mathrm{~kg} / \mathrm{m}^{3}$ at $40^{\circ} \mathrm{C}$ and $20^{\circ} \mathrm{C}$, respectively, were specified by the lubricant manufacturer. This information was complemented by a more thorough study conducted in accordance with BS 188 [23] and 4699 [24]. The oil temperature was monitored throughout the measurement to compensate for variations in the density and viscosity values.

Darcy's law [22] describes the flow of fluids through porous materials at relatively low velocity, where only viscous factors are prevalent. This equation is used to derive the viscous permeability coefficient $\left(\psi_{v}\right)$ and can be written as follows:

$$
\frac{\Delta p}{e}=\frac{Q \cdot \eta}{A \cdot \psi v}
$$


At higher flow rates, inertial effects become significant and Forchheimer's equation [22] is used for the determination of the viscous $\left(\psi_{v}\right)$ and inertial permeability $\left(\psi_{i}\right)$ coefficients:

$$
\frac{\Delta p}{e}=\frac{Q \cdot \eta}{A \cdot \psi_{v}}+\frac{Q^{2} \cdot \rho}{A^{2} \cdot \psi_{i}}
$$

$\mathrm{A}$ is the area of the porous material normal to the direction of the fluid flow in $\mathrm{m}^{2}, \Delta p$ is the pressure drop in $\mathrm{N} / \mathrm{m}^{2}, e$ is the thickness of the test piece in $\mathrm{m}, Q$ is the volume flow rate in $\mathrm{m}^{3} / \mathrm{sec}, \eta$ is the absolute dynamic viscosity in $\mathrm{Ns} / \mathrm{m}^{2}, \rho$ is the density of the test fluid is $\mathrm{kg} / \mathrm{m}^{3}$ is the $\psi_{v}$ viscous permeability coefficient in $\mathrm{m}^{2}$ and $\psi_{i}$ is the inertial permeability coefficient in $\mathrm{m}^{2}$. Equations 5 and 6 describe the relationship between pressure drop $(\Delta p)$ and volume flow rate $(Q)$.

\section{Results \& Discussion}

\subsection{Processing of porous-ceramic bearings}

Twenty six porous ceramic journal bearings and over 60 disc-shaped specimens were successfully processed and ground using 21 different combinations of starch content (10 to 60\% vol.) and alumina powders of $0.45,1.1,2.1,2.7$ and $4 \mu \mathrm{m}$. Journal bearings were primarily of 50 $\mathrm{mm}$ ID, length of $50 \mathrm{~mm}$ and wall thickness of $6 \mathrm{~mm}$. However, a small number of journal bearings of 80 and $150 \mathrm{~mm}$ ID were also produced. Figure 4 illustrates some of the specimens produced during this work.

Ceramic-starch slips based on $7 \mu \mathrm{m}$ alumina were also investigated. However, these invariably segregated before the casting operation. For alumina powders ranging from 2 to $4 \mu \mathrm{m}$, there was 
a maximum starch volumetric solids limit of $40 \%$. Beyond this, journal castings were too weak and cracked or deformed at de-molding. Some disc-shaped specimens were achieved beyond this limit, and this was a direct result of an easier de-molding procedure. Journal bearings with higher starch contents $(50-60 \%$ vol. \%) were only successfully produced with the smaller alumina powders of 0.45 and $1.1 \mu \mathrm{m}$. This was attributed to the better intrinsic particle packing associated with smaller alumina particle sizes, strengthening the casting.

Preliminary trials using $0.45 \mu \mathrm{m}$ alumina and starch contents below $40 \%$ vol. resulted in bearings with relatively high density and very low permeability for porous bearing applications. Therefore, processing at lower starch contents with this size of alumina was not further pursued. The linear shrinkage observed was in the range of $15-18 \%$ for the $0.45 \mu \mathrm{m}$ alumina specimens. The shrinkage increased for each increase of the starch content. The linear shrinkage of specimens processed with alumina powders of $1.1,2.1,2.7$, and $4 \mu \mathrm{m}$, showed only a marginal influence of the starch content, with observed values of around 8, 6, 6.5 and $5.5 \%$, respectively.

\subsection{Density and porosity results}

Figure 5 illustrates the variation of the relative density with the starch and original alumina size of 26 fired and ground 50mm ID, 62mm OD and $50 \mathrm{~mm}$ long journal bearings. Depending on the alumina size and the starch content in the original ceramic slip, the specimens' relative density varied from 51 to $81 \%$. It was evident that there is a direct relationship between the bearings' density and the amount of starch granules present in the original ceramic slip. Higher starch contents resulted in lower density bearings, and vice versa. This effect was expected, as the increasing amount of starch granules burned out during the furnace processing stage, leaves 
an increasing number of voids within the ceramic matrix. The same effect has been also reported by other authors [11-13].

The density trend-lines corresponding to each alumina size showed very similar slopes, the main difference being an offset in relation to each other. Smaller alumina particle sizes, showed a higher y-axis intercept, and vice versa. This effect is mainly attributable to the sintering characteristics of each alumina particle size at the selected sintering conditions. This was also expected, as for a given set of sintering conditions, smaller powders achieve higher densification [25].

The density best fit lines were of linear form:

$$
B_{R}=m \cdot S_{v}+b
$$

Where $B_{R}$ is the specimen's relative density (\%), $m$ and $b$ are constants and $S_{v}$ is the starch solids volumetric percentage $(\%)$. The empirically derived constants for each alumina particle size are summarized in Table 2.

Alumina powders of $0.45 \mu \mathrm{m}$ in size typically approach full density at the sintering conditions used, without any pore formers. Density measurements conducted showed that the experimental data trend-line intercepted the y-axis at $100 \%$, agreeing well with this powder's expected density.

In broad terms, it can be established that the sintered density of the SC porous bearings is first influenced by the sintering rate of the alumina size used, at the chosen sintering conditions. A second influence is the addition of starch, which can increase the porosity a further $20-25 \%$, 
depending on the size of the alumina used. The former has a stronger influence at the lower starch contents, while the latter's influence becomes more evident at the higher starch contents. Density measurements performed on porous ground discs used for the pore size characterization showed that the density of these behaves in essentially the same manner as the density of the journal bearings for each alumina size and starch content formulation. Figure 6 illustrates a comparison of density results between the journal and the disc-shaped specimens, showing a close correlation.

Density measurements conducted on disc-shaped specimens processed with alumina powders ranging from 2 to $4 \mu \mathrm{m}$ and starch contents above $40 \%$ vol. (not achieved for journal bearings), showed that increasing the starch content did not result in a direct increase in porosity. The porosity of these specimens remained at approximately the same level observed at $40 \%$ vol., showing wider data scattering. This was in agreement with previous SC research. Researchers [11] have speculated that this phenomenon is a consequence of minor breakdown of the starch particles during the consolidation stage, resulting in smaller, unstable pores excluded during the sintering operation.

\subsection{Pore size distribution and microstructure results}

Figure 7 illustrates the results from the bubble-test for 25 measurements shown in relation to their original ceramic slip solids composition. The diameter of the pores ranged from 2 to 8.7 $\mu \mathrm{m}$. In general, an increment in the starch content produced larger pores resulting from an increasing number of contacts between starch particles. This behavior has been also observed by other researchers [11]. It was also noted that the specimens processed with larger alumina powder sizes generally resulted in larger pores for the same amount of starch. This was also 
expected, as specimens processed with larger alumina powders had showed higher porosity. The density inconsistencies found at the higher end of the starch contents (50-60\% vol.) were also present during the bubble-test for the 1.1 and $4 \mu \mathrm{m}$ alumina powders. These specimens showed smaller pores than those observed for specimens processed with less starch.

The testing procedure was limited to a pressure of $0.5 \mathrm{MPa}$. As a result, the pores of specimens processed with $0.45 \mu \mathrm{m}$ alumina were too small to be characterized with this method. The same condition applied to the water expulsion test.

Table 3 shows a summary of the results of the water expulsion test in terms of average, maximum, median and modal pore size in relation to the starch content and alumina size. As with the bubble test, it can be generally observed that the mean pore size increases with each increment of the starch content and, consequently porosity. Also, larger pores were observed for the larger alumina sizes for a given amount of starch, as a consequence of their lower densification at the chosen sintering conditions. The average pores ranged from 1.2 to $3.5 \mu \mathrm{m}$. The largest pores, 7.5 and $7.4 \mu \mathrm{m}$, corresponded to $4 \mu \mathrm{m}$ alumina powders at starch contents of 30 and $40 \%$ vol. Given their similar capillary nature, results for maximum pore size of the bubble test and the water expulsion method correlated well. The largest error observed in maximum pore size between the 2 techniques was $1.1 \mu \mathrm{m}$.

Figure 8 shows the typical microstructure of sintered journal bearings produced with $4 \mu \mathrm{m}$ alumina and $20 \%$ vol. starch content. It can be readily appreciated that the voids left by the starch particles dominate, with the pores appearing well dispersed overall, both in terms of distribution and separation. The pores were of a semi-spherical shape and of approximately $20 \mu \mathrm{m}$ in size, correlating well with the size and shape of the starch granules. Similar findings 
have been reported in the literature [11-14]. The microstructure of other specimens made using the same powders composition showed very similar distribution and size of the pores.

Figure 9 show the microstructure of a specimen made using $0.45 \mu \mathrm{m}$ alumina and $40 \%$ vol. starch, at higher magnification. The more advanced stages of the sintering process are more evident for this specimen. Neck and grain growth are clearly more developed. The image shown in this micrograph suggests that the voids left by the starch particles have partially obstructed further densification of the ceramic matrix. It was also apparent that this specimen's microstructure possessed smaller pores than the $4 \mu \mathrm{m}$ specimen (Figure 8); essentially reflecting its shrinkage rate.

As illustrated in Figures 8 and 9, the porous bearings' microstructure consists of solid and voids. The bearing wall becomes permeable at critical porosity $\phi_{c}$ at which the voids become interconnected [26], allowing fluid flow. In the case of externally pressurised ceramic bearings, both flow through the porous wall and bearing performance [6] are greatly influenced by the supply pressure.

In this study, pore interconnectivity has been examined considering the largest capillary equivalent pore obtained via the bubble test (section 3.3) in relation to the specimens' porosity. The presence of the first air bubble indicated pore interconnectivity at a critical porosity. A pressure of $0.5 \mathrm{MPa}$ was used, which is the minimum pressure at which these bearings are expected to work.

Figure 10 illustrates the relationship between open porosity and the maximum equivalent pore. It was observed that the equivalent pore decreases with reduced porosity. The porosity fraction 
threshold at which bubbles were observed was 0.31 . Below this, no bubbles were observed. The data was best fitted to a power equation, similar to that presented by Larson [26] et al:

$\mathrm{d}_{\max }$ is the largest capillary equivalent pore, $\phi$ is the specimen's porosity, and $\phi_{c}$ is the critical porosity. It is believed that deviation from theoretical critical exponent value of 2.0 [27] is due to the microstructure having a pore network comprising $20 \mu \mathrm{m}$ voids left by the starch particles and possibly smaller flow interstices resulting from the partial densification achieved during sintering. The testing pressure boundary of 0.5 Mpa also limited the scope of the experiment.

\subsection{Permeability measurements}

The vast majority of the permeability measurements performed occurred in the laminar flow region, indicating little significance of the inertial permeability coefficient. As illustrated in

Figure 11 , the bearing's viscous permeability coefficient ranged from $1.18 \times 10^{-16}$ to $1.31 \times 10^{-13}$ $\mathrm{m}^{2}$. Permeability was observed to vary with the alumina powder size and the starch content. For every $10 \%$ vol. starch increment, permeability increased. The permeability trend-lines for each alumina powder size showed an offset in relation to each other, with the larger alumina particle sizes showing a higher $y$-axis intercept. This correlated well with measurements of total porosity and pore size. These showed that by increasing the amount of starch in the ceramic slip as well as using larger alumina powders results in a higher porosity and larger pore sizes. This 
consequently results in a larger number of flow interstices within the porous bearing. The best fit line equations for the permeability trend-lines were of the exponential form:

$$
\psi_{v}=k \cdot e^{a \cdot s}
$$

Where $\psi_{v}$ is the viscous permeability coefficient in $\mathrm{m}^{2}, k$ and $a$ are empirical constants and $s$ is starch volumetric constant $(\%)$. The empirically derived constants and the correlation factor $R^{2}$ for each alumina particle size are summarized in Table 4. The maximum repeatability error experienced was of $0.86 \mathrm{~m}^{2}$.

The obtained permeability range lies well within the optimum operational permeability value of $1 \times 10^{-14} \mathrm{~m}^{2}$ for a $50 \mathrm{~mm}$ ID porous hydrostatic journal ultra-precision bearing. This value of permeability can be obtained using different combinations of alumina size and starch content yielding similar levels of porosity, as illustrated in Table 5. Subsequent permeability measurements performed on a larger journal bearing of $80 \mathrm{~mm} \mathrm{ID,} 96 \mathrm{~mm}$ OD and $60 \mathrm{~mm}$ long closely matched those of the $50 \mathrm{~mm}$ ID bearings made with the same slip components, confirming the process consistency.

In this work, alumina porous ceramic journal bearings suitable for ultra-precision spindle applications were successfully processed using maize starch granules as binder and pore former. The bearings produced were of a hollow cylinder shape and had an internal diameter of $50 \mathrm{~mm}$. The bearings' total porosity ranged from 19 to $49 \%$. Porosity showed to be first influenced by the alumina powder size. A second influence was the ceramic slip's starch content, which showed to further increase porosity by as much as $25 \%$. The increase in porosity resulted in 
more, larger pores and this is turn resulted in more permeable structures. For alumina powders of $2.1,2.7$, and $4 \mu \mathrm{m}$, the maximum starch vol. content at which bearings exhibited consistent porosity and permeability was $40 \%$. All ceramic slips prepared with $7 \mu \mathrm{m}$ alumina powders were unsuccessful due to particle segregation. The bearings exhibited average pores ranging from 1.2 to $3.5 \mu \mathrm{m}$. SEM studies conducted on selected specimens revealed the existence of larger pores within the ceramic matrixes microstructure. These were well dispersed and of a semi-spherical shape. The size of these was approximately $20 \mu \mathrm{m}$.

The bearings produced exhibited well defined, reliable and reproducible permeability values ranging from $1.18 \times 10^{-16}$ to $1.04 \times 10^{-13}$. Viscous flow was predominantly observed. The optimum permeability value of $1 \times 10^{-14} \mathrm{~m}^{2}$ for a $50 \mathrm{~mm}$ ID porous hydrostatic journal ultraprecision bearing lies well within this range. Furthermore, the range of permeability obtained using the SC method is wider than previously available and as a result, tailoring of permeability and pore size to suit a wider range of ultra-precision applications is now possible.

Porous discs of $46 \mathrm{~mm}$ diameter and $7 \mathrm{~mm}$ thickness were also produced. The porous discs' density closely matched that of the hollow cylinders. The new method also enabled the processing of porous ceramic journal bearings of up to $150 \mathrm{~mm}$ ID with a typical wall thickness of $10 \mathrm{~mm}$; which were previously unavailable. These new larger bearings could potentially suit a wider range of precision engineering applications.

The new processing method demonstrated to be cost effective, flexible, reproducible and environmentally sound. Sintering temperatures proved to be sufficiently low to conduct this operation using atmospheric furnaces. In addition, no harmful substances have been used or produced. 
Table 6 shows the performance test results of one of these porous ceramic journal bearings in comparison with a standard 5 recess hydrostatic journal bearing [16]. The porous ceramic bearing demonstrated higher stiffness coupled with a more economical performance.

\section{Conclusions}

1. Porous ceramic structures suitable for a variety of ultra-precision applications can be successfully produced by the starch consolidation technique. The journal bearings produced with this technique exhibited well defined, reliable and reproducible

permeability. The optimum permeability of a 50mm ID journal bearing, $1.0 \times 10^{-14} \mathrm{~m}^{2}$, can be achieved using the following alumina size-starch vol. \% formulations: $2.1 \mu \mathrm{m}-$ $32.1 \%, 2.7 \mu \mathrm{m}-31 \%$ and $4 \mu \mathrm{m}-21.4 \%$.

2. The total porosity of the bearings ranged from 19 to $49 \%$. Porosity was first influenced by the alumina powder size. A second influence was the starch content, which showed to further increase porosity by as much as $25 \%$. The increase in porosity resulted in more, larger pores and this is turn resulted in more permeable bearings.

3. The new processing method demonstrated to be cost effective, flexible, reproducible and environmentally sound. 


\section{References:}

1. J. Corbett, R. J. Almond, D. J. Stephenson, Y. B. P. Kwan, "Porous ceramic water hydrostatic bearings for improved accuracy performance" Annals of the CIRP 47 [1] 467-470 (1998).

2. R. J. Almond, J. Corbett, D. J. Stephenson "Porous ceramic water hydrostatic bearings" pp. 147-161 in Total Tribology- Towards an integrated approach. Edited by I. Sherrington, W. B. Rowe, R. J. K Wood. Professional Engineering Publishing, London 2002.

3. J. Corbett, "Precision machine tools and nanotechnology". In proceedings of ESPRC $1^{\text {st }}$ international conference on responsive manufacture, Nottingham 17-18 September 1997, pp. 143-153.

4. N. Taniguchi, "The state of the art of nanotechnology for processing of ultra-precision and ultrafine products" Precision Engineering, 16 [1] 5-24 (1994).

5. F. M. Stansfield, "Hydrostatic bearings for machine tools and similar applications". The machinery publishing co. 1td., Brighton, U.K 1970.

6. A. K. Chattopadhyay, B. C Majumdar, "Steady state solution of finite hydrostatic porous oil journal bearings with tangential velocity slip" Tribology International, 17 [6], 317-323 (1984).

7. G. T. F. Kilmister, "The use of porous materials in externally pressurized gas bearings" Powder Metallurgy 12 [24] 400-409 (1969) 
8. R. B. Howarth, "Externally pressurized porous thrust bearings" ASLE Transactions 19 [4], 293-300 (1976).

9. A. Kumar, N. S. Rao, "Turbulent hybrid journal bearings with porous bush: a steady state performance" Wear, 154, 23-35 (1992).

10. M. Nanko, K. Ishizaki, A. Takata, "Sintering of porous materials by a capsule free HIP process" Ceramic Transactions 31- Porous materials 117-126 (1993).

11. O. Lyckfeldt, J. M. F. Ferreira, "Processing of porous ceramics by starch consolidation" Journal of the European Ceramic Society, 18, 131-140 (1998).

12. M. E. Bowden, M. S. Rippey, "Porous ceramic formed using starch consolidation”, Key Engineering Materials, 206-213, 1957-1960 (2002).

13. E. Gregorova, W. Pabst, "Porosity and pore size control in starch consolidation casting of oxide ceramics- Achievements and problems", Journal of the European Ceramic Society, 27, 669-672 (2007).

14. R. Barea, M. Osendi, P. Miranzo, J. M. F. Ferreira, "Fabrication of Highly Porous Mullite Materials", Journal of the American Ceramic Society, 88[3], 777-779 (2005).

15. I. S. Durazo-Cardenas, Development of porous-ceramic hydrostatic bearings. PhD thesis, Cranfield University, Cranfield, Bedfordshire, 2004.

16. I. S. Durazo-Cardenas, J. Corbett, D. J. Stephenson, "The performance of a porous ceramic hydrostatic journal bearing", Proceedings of the Institution of Mechanical Engineers Part J-Journal Of Engineering Tribology, 224, 81-89 (2009).

17. A. E. Scheidegger "Physical aspects of permeability" pp 125-133 in the physics of flow through porous media. University of Toronto press, Canada, 1960. 
18. British Standards Institution, "Sintered metal materials, excluding hardmetalspermeable sintered metal materials- determination of density, oil content and open porosity" BS EN ISO 2738:2000.

19. British Standard Institution, "Permeable sintered materials- determination of bubble test pore size" BS EN 24003:1993.

20. C. Gelinas, \& R. Angers, Improvement of the dynamic water expulsion method for pore size distribution measurements. Ceramic Bulletin, 65 [9], 1297-1300 (1968).

21. Y. B. P Kwan, D. J. Stephenson, J. R. Alcock, "The dependence of pore size distribution on porosity in hot isostatically pressed porous alumina", Journal of Porous Materials, 8, 119-127 (2001).

22. British Standards Institution, "Powder metallurgical materials and products part 3. Methods of testing sintered materials- Determination of fluid permeability", BS 5600, 1988.

23. British Standards Institution, "Methods for the determination of the viscosity of liquids" BS 188, 1977.

24. British Standards Institution, "Methods for the determination of the density of petroleum products”, BS 4699, 1985.

25. J. S. Reed, "Principles of ceramics processing”, pp 594-606. John Wiley \& Sons, U. S. A., 1995.

26. R. G. Larson, L. E. Scriven, H. T. Davis, "Percolation theory of two phase flow in porous media”, Chemical Engineering Science, 36, $57-73$ (1981).

27. D. B. Gingold, C. J. Lobb, "Percolative conduction in three dimensions" Physical Review B, 42, 8220-8224 (1990). 
Figure 1- Schematic of the bubble test set-up, showing the impregnated disc shaped specimen

Figure 2- Schematic of the modified water expulsion method set-up for disc shaped specimens

Figure 3- Schematic illustrating the permeability measurement principle of porous ceramic journal bearings.

Figure 4- Typical porous ceramic bearings produced. Left: $50 \mathrm{~mm}$ ID bearing, right: $46 \mathrm{~mm}$ diameter disc specimens

Figure 5- The effect of alumina size and starch content on the relative density of porous ceramic journal bearings

Figure 6- Correlation of density between porous ceramic journal bearings and disc-shaped bearings. Units: $\mathbf{g} / \mathrm{cm}^{3}$

Figure 7- The effect of alumina size and starch content on the maximum equivalent pore, obtained via the bubble test. The dotted line illustrates the limit at which increasing the amount of starch consistently resulted in larger pores

Figure 8- Typical microstructure of journal specimens. The figure shows the porosity of a specimen made with $4 \mu \mathrm{m}$ alumina and $20 \%$ Starch vol. The measured permeability and relative density were $3.06 \times 10^{-15} \mathrm{~m}^{2}$ and $62.8 \%$, respectively

Figure 9- Microstructure of a specimen made using $0.45 \mu \mathrm{m}$ alumina and $40 \%$ Starch vol. The use of smaller alumina particles results in more advanced stages of the sintering process

Figure 10- Dependence of the maximum pore size on the porosity of $4 \mu \mathrm{m}$ alumina porous specimens

Figure 11- The effect of alumina size and starch content on the permeability $\left(\mathrm{m}^{2}\right)$ of porous ceramic journal bearings 


\begin{tabular}{cccc}
\hline Material & Supplier & $\begin{array}{c}\text { Median particle size } \\
(\mu \mathbf{m})\end{array}$ & Surface area $\left(\mathbf{m}^{2} / \mathbf{g}\right)$ \\
\hline Maize Starch & CERESTAR & $10-20$ & -- \\
03401 & UK Ltd & & -- \\
Dispersant Dispex & Allied colloids & -- & 7.5 \\
A40 & Ltd & 0.45 & 2.9 \\
$\mathrm{Al}_{2} \mathrm{O}_{3}$ (RA 45E) & ALCAN & 1.1 & 2.2 \\
$\mathrm{Al}_{2} \mathrm{O}_{3}$ (RA 7) & ALCAN & 2.1 & 3.7 \\
$\mathrm{Al}_{2} \mathrm{O}_{3}$ (RA 10) & ALCAN & 2.7 & 1.8 \\
$\mathrm{Al}_{2} \mathrm{O}_{3}$ (RA 15) & ALCAN & 4 & 0.7 \\
$\mathrm{Al}_{2} \mathrm{O}_{3}$ (RA 12) & ALCAN & 7 & -- \\
$\mathrm{Al}_{2} \mathrm{O}_{3}$ (MA4LS) & ALCAN & -- & \\
$\mathrm{De}_{\text {ionized water }}$ & -- & & \\
\hline
\end{tabular}

Table 1- Raw materials used in the formulation of ceramics slips for processing porous ceramic hydrostatic bearings

\begin{tabular}{cccc}
\hline $\begin{array}{c}\text { Powder median size } \\
(\boldsymbol{\mu m})\end{array}$ & $\mathbf{m}$ & $\mathbf{b}$ & $\mathbf{R}^{\mathbf{2}}$ \\
\hline 0.45 & -0.66 & 100.07 & 0.99 \\
1.1 & -0.47 & 75.77 & 0.97 \\
2.1 & -0.59 & 78.49 & 0.99 \\
2.7 & -0.54 & 77.72 & 0.93 \\
4 & -0.49 & 71 & 0.98 \\
\hline
\end{tabular}

Table 2- Porous ceramic journal relative density best-fit line constants by alumina size 


\begin{tabular}{cccccccc}
\hline $\begin{array}{c}\text { Specimen } \\
\#\end{array}$ & $\begin{array}{c}\text { Alumina } \\
\text { Size }(\boldsymbol{\mu m})\end{array}$ & $\begin{array}{c}\text { Starch } \\
\text { Vol. } \%\end{array}$ & $\begin{array}{c}\text { Open } \\
\text { Porosity } \\
(\boldsymbol{\%})\end{array}$ & $\begin{array}{c}\text { Dia. } \\
\text { Average } \\
\text { Pore }(\boldsymbol{\mu m})\end{array}$ & $\begin{array}{c}\text { Dia. } \\
\text { Maximum } \\
\text { Pore }(\boldsymbol{\mu m})\end{array}$ & $\begin{array}{c}\text { Median } \\
(\boldsymbol{\mu m})\end{array}$ & $\begin{array}{c}\text { Modal } \\
(\boldsymbol{\mu m})\end{array}$ \\
\hline 1 & 1.1 & 40 & 40.3 & 1.3 & 3.8 & 0.7 & 0.6 \\
2 & 1.1 & 50 & 40.0 & 1.2 & 2.3 & 0.8 & 0.7 \\
3 & 2.1 & 30 & 38.5 & 1.3 & 2.8 & 0.7 & 0.6 \\
4 & 2.1 & 40 & 45.5 & 2.4 & 5.6 & 1.6 & 1.5 \\
5 & 2.7 & 30 & 38.9 & 1.3 & 3.8 & 0.8 & 0.6 \\
6 & 2.7 & 40 & 46.3 & 2.5 & 5.6 & 1.6 & 1.5 \\
7 & 4 & 10 & 34.9 & 1.2 & 3.3 & 0.8 & 0.6 \\
8 & 4 & 10 & 33.6 & 1.2 & 2.8 & 0.6 & 0.6 \\
9 & 4 & 20 & 39.5 & 1.5 & 4.5 & 0.8 & 0.8 \\
10 & 4 & 30 & 45.2 & 2.6 & 7.5 & 1.5 & 1.2 \\
11 & 4 & 40 & 49.4 & 3.5 & 7.4 & 2.3 & 2.2 \\
\hline
\end{tabular}

Table 3- Water expulsion pore size distribution results

\begin{tabular}{cccc}
\hline Powder size median $(\boldsymbol{\mu m})$ & $\mathbf{k}$ & $\mathbf{a}$ & $\mathbf{R}^{2}$ \\
\hline 0.45 & $1.49 \times 10^{-17}$ & 0.1073 & 0.99 \\
1.1 & $7.21 \times 10^{-17}$ & 0.1011 & 0.91 \\
2.1 & $6.10 \times 10^{-17}$ & 0.1588 & 0.99 \\
2.7 & $1.91 \times 10^{-16}$ & 0.1278 & 0.99 \\
4 & $4.36 \times 10^{-16}$ & 0.1464 & 0.92 \\
\hline
\end{tabular}

Table 4- Curve fitting constants obtained for viscous permeability of porous ceramic journal bearings by alumina size

\begin{tabular}{ccc}
\hline $\begin{array}{c}\text { Alumina median size } \\
(\boldsymbol{\mu m})\end{array}$ & $\begin{array}{c}\text { Starch content } \\
(\text { vol. } \%)\end{array}$ & Relative density $(\%)$ \\
\hline 2.1 & 32.1 & 59.6 \\
2.7 & 31 & 61 \\
4 & 21.4 & 60.5 \\
\hline
\end{tabular}

Table 5- combinations of powders, alumina and starch, yielding the optimum value of permeability for a 50mm ID journal bearing and the expected density based on equations 7 and 9, respectively 


\begin{tabular}{ccc}
\hline Performance parameter & Porous ceramic & Conventional Hydrostatic \\
\hline Static stiffness $(\mathrm{N} / \mu \mathrm{m})$ & 43 & 22 \\
Rotational stiffness $(\mathrm{N} / \mu \mathrm{m})$ & 80 & 31 \\
Lubricant flow rate $(\mathrm{lpm})$ & 1.38 & 2.17 \\
Pumping power $(\mathrm{W})$ & 23 & 36 \\
Temperature rise $\left({ }^{\circ} \mathrm{C}\right)$ & 0.8 & 1.6 \\
\hline
\end{tabular}

Table 6- Typical experimental data of a SC porous ceramic journal bearing when compared with a conventional hydrostatic journal bearing. The table illustrates a clear improvement on stiffness while performing more efficiently, i.e. lower lubricant flow and hence power required 